\title{
An Earth-system perspective of the global nitrogen cycle
}

\author{
Nicolas Gruber \& James N. Galloway
}

\begin{abstract}
With humans having an increasing impact on the planet, the interactions between the nitrogen cycle, the carbon cycle and climate are expected to become an increasingly important determinant of the Earth system.
\end{abstract}

\begin{abstract}
The massive acceleration of the nitrogen cycle as a result of the production and industrial use of artificial nitrogen fertilizers worldwide has enabled humankind to greatly increase food production, but it has also led to a host of environmental problems, ranging from eutrophication of terrestrial and aquatic systems to global acidification. The findings of many national and international research programmes investigating the manifold consequences of human alteration of the nitrogen cycle have led to a much improved understanding of the scope of the anthropogenic nitrogen problem and possible strategies for managing it. Considerably less emphasis has been placed on the study of the interactions of nitrogen with the other major biogeochemical cycles, particularly that of carbon, and how these cycles interact with the climate system in the presence of the ever-increasing human intervention in the Earth system ${ }^{1}$. With the release of carbon dioxide $\left(\mathrm{CO}_{2}\right)$ from the burning of fossil fuels pushing the climate system into uncharted territor $\mathrm{y}^{2}$, which has major consequences for the functioning of the global carbon cycle, and with nitrogen having a crucial role in controlling key aspects of this cycle, questions about the nature and importance of nitrogen-carbon-climate interactions are becoming increasingly pressing. The central question is how the availability of nitrogen will affect the capacity of Earth's biosphere to continue absorbing carbon from the atmosphere (see page 289), and hence continue to help in mitigating climate change. Addressing this and other open issues with regard to nitrogen-carbon-climate interactions requires an Earth-system perspective that investigates the dynamics of the nitrogen cycle in the context of a changing carbon cycle, a changing climate and changes in human actions.
\end{abstract}

\section{The anthropogenic perturbation of the nitrogen cycle}

Nitrogen is a fundamental component of living organisms; it is also in short supply in forms that can be assimilated by plants in both marine and land ecosystems. As a result, nitrogen has a critical role in controlling primary production in the biosphere. Nitrogen is also a limiting factor for the plants grown by humans for food. Without the availability of nitrogenous fertilizer produced by the industrial process known as the Haber-Bosch process, the enormous increase in food production over the past century, which in turn has sustained the increase in global population, would not have been possible. All the nitrogen used in food production is added to the environment, as is the nitrogen emitted to the atmosphere during fossil-fuel combustion. In the 1990s, these two sources of anthropogenic nitrogen to the environment amounted to more than 160 teragrams (Tg) N per year (Fig. 1). On a global basis, this is more than that supplied by natural biological nitrogen fixation on land (110 Tg N per year) or in the ocean (140 Tg N per year) (Fig. 1). Given expected trends in population, demand for food, agricultural practices and energy use, anthropogenic nitrogen fluxes are fated to increase; that is, humans are likely to be responsible for doubling the turnover rates not only of the terrestrial nitrogen cycle but also of the nitrogen cycle of the entire Earth.

The negative consequences of these nitrogen additions are substantial and manifold, ranging from eutrophication of terrestrial and aquatic systems to global acidification and stratospheric ozone loss ${ }^{3}$. Of particular concern is the fact that chemical transformations of nitrogen along its transport pathway in the environment often lead to a cascade of effects. For example, an emitted molecule of nitrogen oxide can first cause photochemical smog and then, after it has been oxidized in the atmosphere to nitric acid and deposited on the ground, can lead to ecosystem acidification and eutrophication. Although there is still much to understand about the implications of nitrogen accumulation in the environment, there is also much to understand about how the increased availability of nitrogen interacts with other biogeochemical element cycles and how those interactions affect global climate change.

\section{Nitrogen and the perturbation of other element cycles}

The human acceleration of the nitrogen cycle did not occur in isolation, as humans have altered the cycles of many other elements as well, most notably those of phosphorus, sulphur and carbon ${ }^{1}$. Of particular relevance is the acceleration of the global carbon cycle, because of the central role of atmospheric $\mathrm{CO}_{2}$ in controlling climate ${ }^{4}$. As a result of the burning of fossil fuels and carbon emissions from land-use change, atmospheric $\mathrm{CO}_{2}$ has increased to levels that are more than $30 \%$ above those of pre-industrial times. This increase in atmospheric $\mathrm{CO}_{2}$ has been identified as the primary cause for the observed warming over the past century, particularly that of the past 30 years ${ }^{2}$.

The perturbations of the global nitrogen and carbon cycles caused by human activity are in part linked to each other. This is mostly a result of the atmosphere's being very efficient in spreading the nitrogen oxides and ammonia emitted as a result of energy and food production, and also because this nitrogen is deposited on the ground in a form that is readily available to plants, thereby stimulating productivity and enhancing the uptake of $\mathrm{CO}_{2}$ from the atmosphere.

The existence of a largely unexplained, but substantial, carbon sink in the Northern Hemisphere terrestrial biosphere ${ }^{5}$ (that is, in exactly the region that receives most of the anthropogenic nitrogen from the atmosphere) would seem to support this conjecture. However, nitrogenaddition and modelling studies suggest that the contribution of nitrogen fertilization to the Northern Hemisphere carbon land sink has been small. This issue needs to be resolved, because the different processes that are being considered to explain the current Northern Hemisphere carbon sink have very different future trajectories. If $\mathrm{CO}_{2}$ fertilization is responsible - that is, the direct effect of elevated $\mathrm{CO}_{2}$ on plant growth - one could expect this process to continue largely unabated into the future. If nitrogen fertilization is responsible, however, one could expect 
the effect to level off in the future, primarily because the effect tends to decrease with increasing nitrogen load ${ }^{6}$.

The deposition of biologically available nitrogen into the ocean could also fertilize the ocean's biosphere and stimulate additional uptake of $\mathrm{CO}_{2}$ there. On a global scale, the atmospheric deposition is small relative to the amount of nitrogen that is being fixed into organic matter and exported to depth, but it is an important source of external reactive nitrogen, being second in importance to naturally occurring marine nitrogen fixation (Fig. 1). The relative contribution of atmospherically derived reactive nitrogen to the total nitrogen demand can be much larger in certain regions, particularly in coastal regions downwind of the major Northern Hemisphere sources, and in regions where the vertical supply of reactive nitrogen from below is very restricted, such as the central subtropical ocean gyres.

The coastal ocean also receives a significant amount of anthropogenic nitrogen through rivers (Fig. 1). In some areas, this has led to well documented coastal eutrophication ${ }^{7}$, but the general consensus has been that the anthropogenic increase in river-derived nitrogen has had no impact on the open ocean.

\section{Elemental interactions of the natural cycles}

The natural (unperturbed) components of the carbon and nitrogen cycles are even more tightly coupled than are the anthropogenic components (Fig. 1). This is a direct consequence of the presence of life, which links the elemental cycles of carbon, nitrogen and other elements at the molecular level, as a result of the constitutional need of organisms for these elements to build their tissues. This coupling occurs with specific elemental stoichiometries, whose values and flexibilities determine not only the relative speed at which the different cycles are coupled, but also how tight the coupling is ${ }^{8}$. In the ocean, the $\mathrm{C} / \mathrm{N}$ ratio of the autotrophic phytoplankton responsible for nearly all marine photosynthesis varies remarkably little, whereas the $\mathrm{C} / \mathrm{N}$ ratio of terrestrial plants is substantially more variable and also tends to be larger than that for marine phytoplankton.

Understanding the processes that control the $\mathrm{C} / \mathrm{N}$ ratios of autotrophic organisms on land and in the ocean is of critical importance for understanding the global nitrogen and carbon cycles and the Earth system. Given nitrogen's importance in limiting global primary production, about half of which occurs on land and half in the ocean ${ }^{9}$, systematic alterations of the $\mathrm{C} / \mathrm{N}$ ratios of either marine or terrestrial autotrophs would permit Earth's biosphere to undergo rapid and large changes in productivity without the need to alter the amount of biologically available nitrogen. Such productivity changes would directly affect atmospheric $\mathrm{CO}_{2}$, and consequently climate. In contrast, if the $\mathrm{C} / \mathrm{N}$ ratios of autotrophic organisms were constrained to vary only within narrow bounds, Earth's productivity would be relatively tightly coupled to the amount of biologically available nitrogen, permitting productivity to vary only within restricted limits unless there were processes that altered the amount of biologically available nitrogen.

\section{Changing reactive nitrogen inventories}

Biological nitrogen fixation and denitrification (which refers here to all processes that convert reactive forms of nitrogen to molecular nitrogen $\left(\mathrm{N}_{2}\right)$, which cannot be used directly as a nitrogen source by most organisms) are the most important natural processes that could alter the amount of reactive nitrogen in the Earth system, and hence alter the global carbon cycle and climate, without changing the $\mathrm{C} / \mathrm{N}$ ratio of autotrophs (Fig. 1).

In the ocean, the magnitude of biological nitrogen fixation and denitrification and the corollary question of how well these two processes balance each other are currently hotly debated. Current estimates of the marine nitrogen budget arrive at either more-or-less balanced budgets (albeit with large uncertainties) ${ }^{10}$ or a very large deficit, driven primarily by a much larger denitrification estimate ${ }^{11}$. Observations so far are not adequate to clearly refute either estimate, but there is no doubt that the marine nitrogen cycle is very dynamic, with a residence time for reactive nitrogen - the time for the total pool of reactive nitrogen to be turned over - of less than 3,000 years ${ }^{10}$.

One is immediately tempted to ask what couples biological nitrogen fixation and denitrification in the ocean, so that the amount of fixed nitrogen in the ocean remains relatively stable over timescales longer than a few thousand years. Although many hypotheses have been put

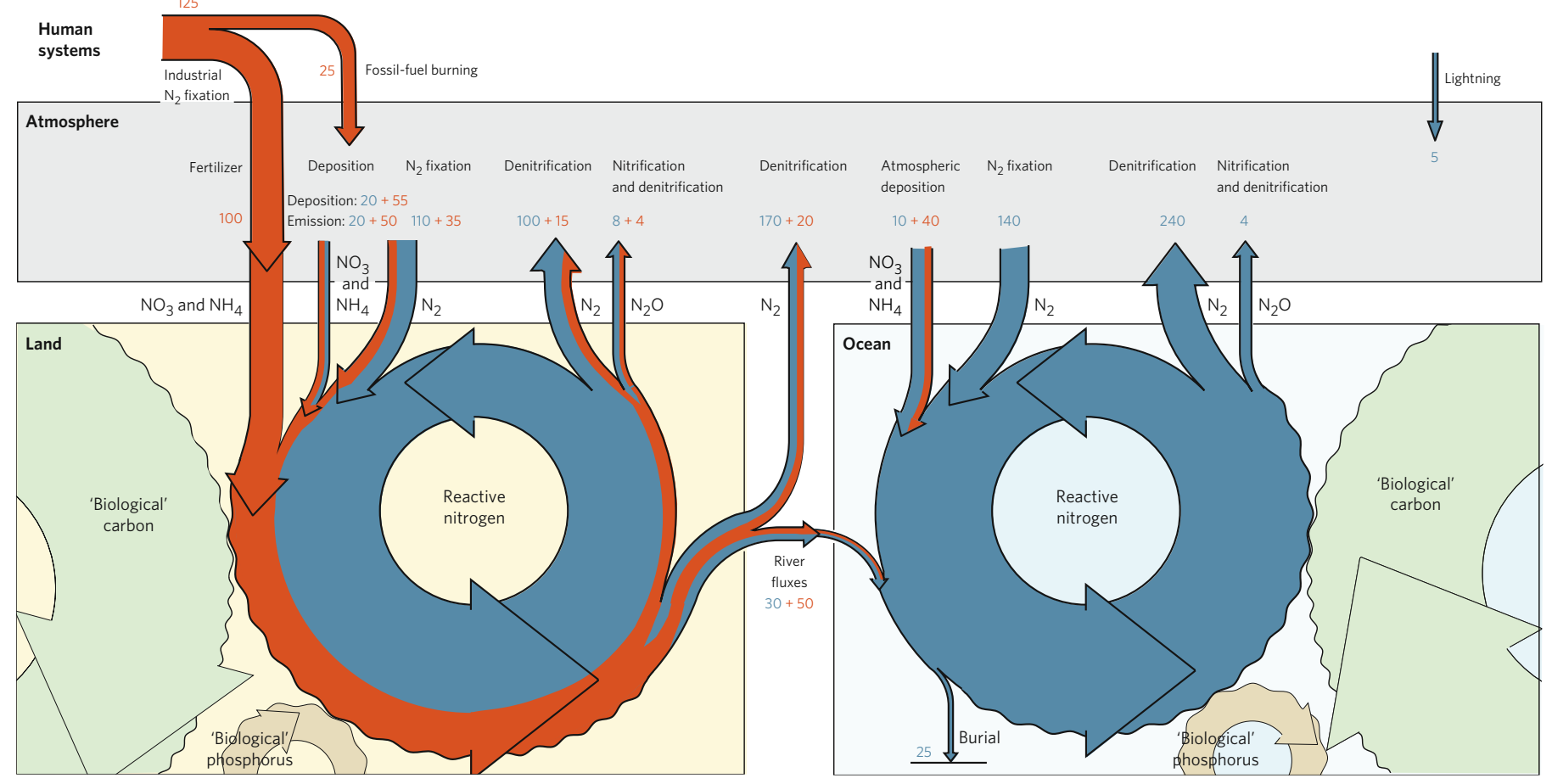

Figure 1 Depiction of the global nitrogen cycle on land and in the ocean. Major processes that transform molecular nitrogen into reactive nitrogen, and back, are shown. Also shown is the tight coupling between the nitrogen cycles on land and in the ocean with those of carbon and phosphorus. Blue fluxes denote 'natural' (unperturbed) fluxes; orange fluxes denote anthropogenic perturbation. The numbers (in $\mathrm{Tg} \mathrm{N}$ per year) are values for the 1990s (refs 13, 21). Few of these flux estimates are known to better than $\pm 20 \%$, and many have uncertainties of $\pm 50 \%$ and larger $^{13,21}$. 
forward, current evidence suggests that the marine phosphorus cycle is crucial in stabilizing the marine nitrogen cycle $^{12}$, with other factors such as light, temperature and iron availability having a modulating effect. This hypothesis essentially makes the marine nitrogen cycle a slave to that of phosphate, making phosphate the ultimate limiting nutrient that is, the nutrient that puts an upper limit on marine productivity and the ocean carbon cycle on timescales of thousands of years and longer.

In contrast with the marine realm, relatively few studies have attempted to scale up local estimates of biological nitrogen fixation and denitrification in terrestrial systems to the global scale ${ }^{13}$, making the terrestrial reactive nitrogen budget as tentative as that of the ocean. When all estimated losses of nitrogen from terrestrial systems are subtracted from estimates of nitrogen inputs to these systems, the balance - which includes the accumulation of reactive nitrogen in the system - is statistically indistinguishable from zero. However, there are such large uncertainties in the individual estimates that estimates of accumulation made by such difference methods are meaningless, other than to say that it is occurring. As a result of a somewhat smaller pool size, the total reactive nitrogen on land is turned over even more rapidly than that in the ocean, having a mean residence time of only about 500 years.

Nearly half of global terrestrial denitrification occurs in freshwater systems ${ }^{14}$, with most of the reactive nitrogen that is denitrified coming from the land. Thus, terrestrial nitrogen cycling is characterized by a strong lateral transport component, which brings reactive nitrogen from the land, where sources of reactive nitrogen tend to exceed local denitrification, into freshwater systems, where the opposite is the case. There, most of the land-derived reactive nitrogen is removed, leaving a comparatively small flux of reactive nitrogen entering the ocean ${ }^{14}$. This one-way conveyor prevents the terrestrial nitrogen cycle from having such a tight bidirectional interaction between biological nitrogen fixation and denitrification as is hypothesized to occur in the ocean. Thus, the question of what controls nitrogen fixation and denitrification in terrestrial systems, and what keeps the terrestrial nitrogen cycle in balance on timescales longer than a few thousand years, is even more perplexing than for marine systems.

\section{Past changes as a guide?}

A good test of our knowledge of the global nitrogen cycle and of its interaction with the carbon cycle and climate is the past. In the past million years, Earth's climate has undergone many large swings, to which the global nitrogen cycle has responded sensitively (Fig. 2).

Perhaps the most informative record of the past activity of the global nitrogen cycle is that of atmospheric nitrous oxide $\left(\mathrm{N}_{2} \mathrm{O}\right)$, as its concentration is primarily determined by the magnitudes of nitrification (that is, the oxidation of ammonia to nitrite and, subsequently, to nitrate) and denitrification - two central processes of the global nitrogen cycle. Over the past 60,000 years (Fig. 2), $\mathrm{N}_{2} \mathrm{O}$ has undergone large and relatively rapid changes that are synchronized with climate variations, with cold periods generally corresponding to low $\mathrm{N}_{2} \mathrm{O}$ concentrations, and vice versa. However, the response of $\mathrm{N}_{2} \mathrm{O}$ to these climate changes is not linear but is characterized by hystereses and enhanced responses to prolonged climatic perturbations ${ }^{15}$. As the ocean and the land contribute about equally to natural $\mathrm{N}_{2} \mathrm{O}$ emissions, both systems could be responsible for these changes in atmospheric $\mathrm{N}_{2} \mathrm{O}$, but attribution has remained elusive so far. Despite this lack of understanding of the underlying processes forcing these changes, the close correspondence between atmospheric $\mathrm{CO}_{2}$ levels, temperature and atmospheric $\mathrm{N}_{2} \mathrm{O}$ concentrations demonstrate that the nitrogen cycle is closely coupled to variations in the climate system and in the carbon cycle.

Data from the marine environment underscore this coupling. Measurements of the ${ }^{15} \mathrm{~N} /{ }^{14} \mathrm{~N}$ ratio of organic nitrogen from marine sediments in the Arabian Sea (Fig. 2) show rapid variations that are remarkably similar to those of atmospheric $\mathrm{CO}_{2}$ and climate. These ${ }^{15} \mathrm{~N} /{ }^{14} \mathrm{~N}$ variations largely reflect changes in marine denitrification, with high values characterizing periods with elevated denitrification - that is, high losses of reactive nitrogen from the marine realm - potentially leading to a reduction in the strength of marine productivity. Given the correspondence between high

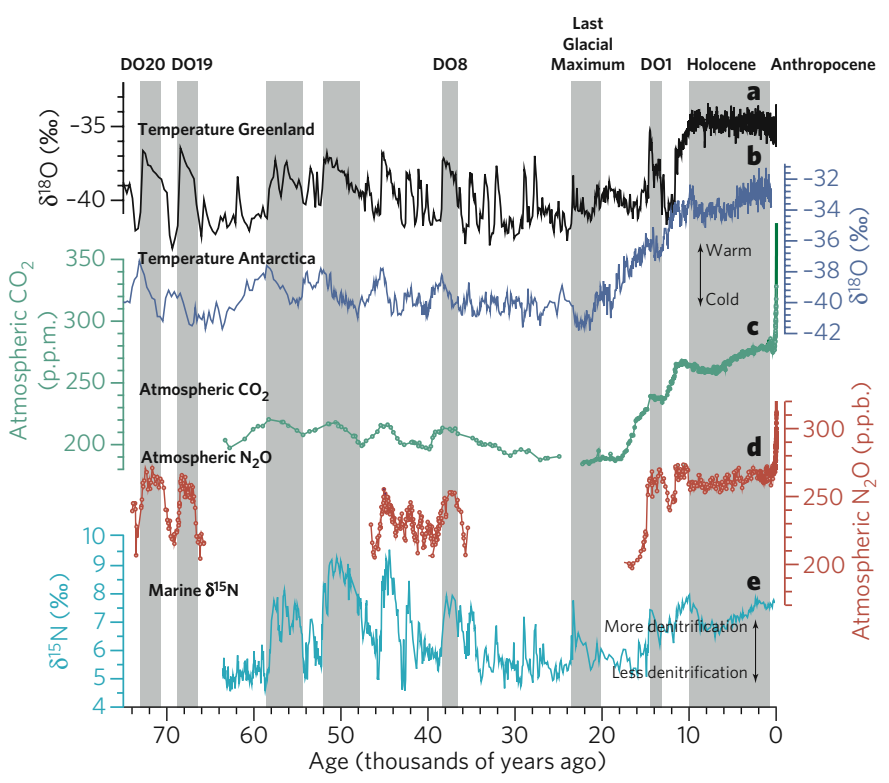

Figure 2 | Changes in the climate system and the global nitrogen and carbon cycles over the past 75,000 years. Data are plotted against age before the year 1950, using the Greenland-based GISP2 age scale. a, The ${ }^{18} \mathrm{O} /{ }^{16} \mathrm{O}$ ratio $\left(\delta^{18} \mathrm{O}\right)$ of ice from Greenland, as a proxy for Greenland temperature ${ }^{22}$. b, The $\delta^{18} \mathrm{O}$ of ice from Antarctica, as a proxy for Antarctic temperature ${ }^{22}$. c, Atmospheric $\mathrm{CO}_{2}$ concentrations as recorded in air bubbles from various Antarctic ice cores (see ref. 23 for original references) and direct atmospheric measurements since 1958. d, Atmospheric $\mathrm{N}_{2} \mathrm{O}$ concentrations as recorded in air bubbles from various Antarctic and Greenland ice cores ${ }^{15}$ and direct atmospheric measurements since the late $1970 \mathrm{~s} . \mathrm{e},{ }^{15} \mathrm{~N} /{ }^{14} \mathrm{~N}$ ratio $\left(\delta^{15} \mathrm{~N}\right)$ of organic nitrogen from a marine sediment core from the Oman margin in the Arabian Sea ${ }^{16}$ \% $\%$, parts per thousand; DO, DansgaardOeschger event; p.p.b., parts per billion; p.p.m., parts per million.

ocean denitrification rates and high atmospheric $\mathrm{CO}_{2}$ levels, it has been suggested that changes in the marine nitrogen cycle could be a leading cause of the observed variations in the concentration of atmospheric $\mathrm{CO}_{2}$ (ref. 16). Such a nitrogen-based hypothesis to explain the large variations in atmospheric $\mathrm{CO}_{2}$ concentrations across the glacial-interglacial periods of the past 650,000 years is tempting, as the causes of these changes are still not clearly identified and represent one of the greatest enigmas of global carbon-cycle research. However, a recent assessment concluded that it is unlikely that changes in the marine nitrogen cycle were the key drivers for the past changes in $\mathrm{CO}_{2}$ levels, although they probably contributed to it $^{10}$.

Another key message from the records of the past is that anthropogenic perturbation of the global carbon and nitrogen cycles already pushed these cycles into uncharted territory decades ago, with atmospheric $\mathrm{CO}_{2}$ and $\mathrm{N}_{2} \mathrm{O}$ now having attained levels that have, almost certainly, not been seen on this planet for the past 650,000 years $^{2}$.

\section{The future}

What will the future hold? Future assessments are rife with uncertainties, but it is difficult to conceive a trajectory of global development up to at least 2050, and possibly beyond, that will not result in increased industrial production of nitrogen-based fertilizers and increased emissions of fossil-fuel $\mathrm{CO}_{2}$ (ref. 2). The level that atmospheric $\mathrm{CO}_{2}$ will attain in the future depends not only on the rate of anthropogenic emissions, but to a substantial degree on the future behaviour of the Earth system ${ }^{17}$, which so far has helped to mitigate the anthropogenic $\mathrm{CO}_{2}$ problem substantially by absorbing roughly half of total $\mathrm{CO}_{2}$ emissions $^{4}$ (see page 297). With the atmospheric $\mathrm{CO}_{2}$ levels currently projected up to 2100 , one expects an additional warming of between a few and several degrees Celsius ${ }^{2}$. Thus, there is little doubt that the global nitrogen cycle will come under increasing pressure, not only from direct anthropogenic perturbations but also from the consequences of 


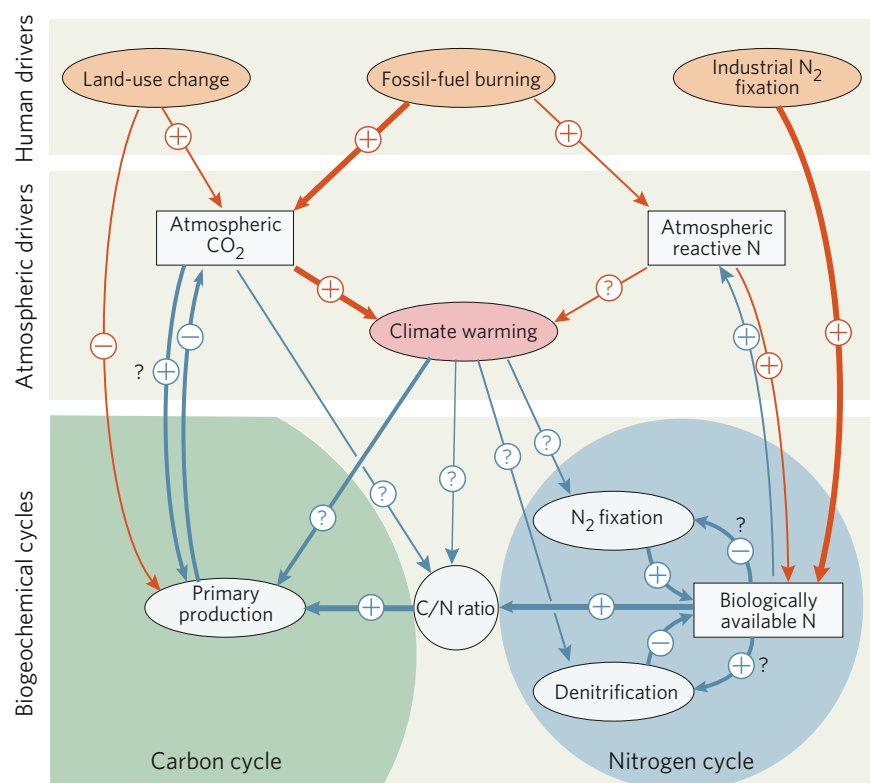

Figure 3 | Nitrogen-carbon-climate interactions. The main anthropogenic drivers of these interactions during the twenty-first century are shown. Plus signs indicate that the interaction increases the amount of the factor shown; minus signs indicate a decrease; question marks indicate an unknown impact (or, when next to a plus or minus sign, they indicate a high degree of uncertainty). Orange arrows denote the direct anthropogenic impacts, and blue arrows denote natural interactions, many of which could also be anthropogenically modified. Arrow thickness denotes strength of interaction. Only selected interactions are shown.

climate change. At the same time, the response of the global nitrogen cycle to these forcings could have major consequences for the further evolution of climate change. It could have either an enforcing effect, by reducing the ability of the Earth system to absorb anthropogenic $\mathrm{CO}_{2}$ (positive feedback), or a reducing effect, by increasing the uptake of anthropogenic $\mathrm{CO}_{2}$ (negative feedback).

There are too many possible interactions to assess in this brief article, but some of the interacting drivers of the nitrogen cycle during the twenty-first century are presented in Fig. 3. From the perspective of nitrogen-carbon-climate interactions, the following two processes need special consideration: decoupling of the nitrogen and carbon cycling through changes in the $\mathrm{C} / \mathrm{N}$ ratios of autotrophs; and changes in the reactive nitrogen inventory of the Earth system through changes in nitrogen fixation (industrial and biological), denitrification or mobilization.

An example for the first process is the recent finding that ocean acidification resulting from the ocean's taking up anthropogenic $\mathrm{CO}_{2}$ might lead to an increase in the $\mathrm{C} / \mathrm{N}$ uptake ratio of marine phytoplankton ${ }^{18}$ and enhanced nitrogen fixation ${ }^{19}$. If this tentative result holds up, these changes would make the marine biosphere act as a negative feedback for climate change, as the resulting enhanced fixation of carbon would draw additional carbon from the atmosphere, thus reducing the accumulation of anthropogenic $\mathrm{CO}_{2}$ in the atmosphere.

A good example of the second process is the role of the reactive nitrogen inventory in the future productivity of terrestrial ecosystems. The current generation of coupled climate-carbon-cycle models used for making projections of Earth's climate for the remainder of the twenty-first century and beyond ${ }^{17}$ do not consider nitrogen limitation of the terrestrial biosphere but generally assume a strong $\mathrm{CO}_{2}$ fertilization effect. In several models, the magnitude of this fertilization-induced uptake amounts in the next 100 years to several hundred petagrams of carbon, which requires several thousand teragrams of nitrogen. This amount of reactive nitrogen is clearly not available in the Earth system. Thus, nitrogen limitation is bound to substantially determine the ability of the terrestrial biosphere to act as a $\mathrm{CO}_{2}$ sink in the future, although the detailed interactions between increased fertility, $\mathrm{C} / \mathrm{N}$ ratios in plants and soils and microbial activity are only poorly understood. The lack of consideration of this whole class of climate-relevant feedbacks in the current Earth system leads to substantial uncertainties in climate-change projections ${ }^{17}$.

Such uncertainties urgently need to be reduced, because major political, societal and economic decisions need to be undertaken if humans are serious in addressing the challenges associated with future climate change. The reduction of these uncertainties requires a major concerted effort that includes the entire set of tools and approaches available to researchers who work in the fields of carbon and nitrogen studies. A particularly pressing need is for ecosystem-manipulation studies that address the interactions of multiple perturbation factors.

Can management of the global nitrogen cycle help to mitigate climate change? Although various options have been proposed in the past, such as fertilization of forests and marine ecosystems, the scientific consensus is that their effectiveness is generally low, and that unintended negative consequences could be serious ${ }^{20}$. Therefore, the best strategy for reducing the potential threat from human activity in the 'Anthropocene' - this modern age in which humans have a significant impact on the Earth system - is to reduce the burning of fossil fuels.

Nicolas Gruber is in the Environmental Physics group, Institute of Biogeochemistry and Pollutant Dynamics, ETH Zurich, Universitätstrasse 16, 8092 Zurich, Switzerland. James N. Galloway is in the Environmental Sciences Department, University of Virginia, 291 McCormick Road, Charlottesville, Virginia 22904, USA.

1. Falkowski, P. G. et al. The global carbon cycle: a test of our knowledge of Earth as a system. Science 290, 291-296 (2000)

2. Intergovernmental Panel on Climate Change. in Climate Change 2007: The Physical Science Basis. Contribution of Working Group I to the Fourth Assessment Report of the Intergovernmental Panel on Climate Change (eds Solomon, S. et al.) 1-18 (Cambridge Univ. Press, Cambridge, UK, 2007).

3. Galloway, J. N. et al. The nitrogen cascade. Bioscience 53, 341-356 (2003)

4. Sarmiento, J. L. \& Gruber, N. Anthropogenic carbon sinks. Physics Today 55, 30-36 (2002). . Schimel, D. S. et al. Recent patterns and mechanisms of carbon exchange by terrestrial ecosystems. Nature 414, 169-172 (2001).

6. Hyvönen, R. et al. Impact of long-term nitrogen addition on carbon stocks in trees and soils in northern Europe. Biogeochemistry, doi:10.1007/s10533-007-9121-3 (2007).

7. Rabalais, N. N. Nitrogen in aquatic environments. Ambio 31, 102-112 (2002).

8. Sterner, R. W. \& Elser, J. J. Ecological Stoichiometry: the Biology of Elements from Molecules to the Biosphere (Princeton Univ. Press, Princeton, 2002).

9. Field, C. B., Behrenfeld, M. J., Randerson, J. \& Falkowski, P. Primary productivity of the biosphere: an integration of terrestrial and oceanic components. Science $\mathbf{2 8 1}, \mathbf{2 3 7 - 2 4 0}$ (1998).

10. Gruber, N. in Carbon Climate Interactions (eds Oguz, T. \& Follows, M.) 97-148 (Kluwer Academic, Dordrecht, 2004).

11. Codispoti, L. A. An oceanic fixed nitrogen sink exceeding $400 \mathrm{Tg} \mathrm{N}^{-1} \mathrm{vs}$ the concept of homeostasis in the fixed-nitrogen inventory. Biogeosciences 3, 1203-1246 (2006)

12. Deutsch, C., Sarmiento, J. L., Sigman, D. M., Gruber, N. \& Dunne, J. P. Spatial coupling of nitrogen inputs and losses in the ocean. Nature 445, 163-167 (2007).

13. Galloway, J. N. et al. Nitrogen cycles: past, present, future. Biogeochemistry 70, 153-226 (2004).

14. Seitzinger, S. et al. Denitrification across landscapes and waterscapes: a synthesis. Ecol. Appl. 16, 2064-2090 (2006)

15. Flückiger, J. et al. $\mathrm{N}_{2} \mathrm{O}$ and $\mathrm{CH}_{4}$ variations during the last glacial epoch: insight into global processes. Global Biogeochem. Cycles 18, 1-14 (2004)

16. Altabet, M. A., Higginson, M. J. \& Murray, D. W. The effect of millennial-scale changes in Arabian Sea denitrification on atmospheric $\mathrm{CO}_{2}$. Nature 415, 159-162 (2002).

17. Denman, K. L. et al. in Climate Change 2007: The Physical Science Basis. Contribution of Working Group I to the Fourth Assessment Report of the Intergovernmental Panel on Climate Change (eds Solomon, S. et al.) 499-587 (Cambridge Univ. Press, Cambridge, UK, 2007)

18. Riebesell, $U$. et al. Enhanced biological carbon consumption in a high $\mathrm{CO}_{2}$ ocean. Nature 450, 545-548 (2007)

19. Barcelos e Ramos, J., Biswas, H., Schulz, K. G., LaRoche, J. \& Riebesell, U. Effect of rising atmospheric carbon dioxide on the marine nitrogen fixer Trichodesmium. Global Biogeochem. Cycles 21, doi:10.1029/2006GB002898 (2007).

20. Austin, A. T. et al. in Interactions of the Major Biogeochemical Cycles (eds Melillo, J. M., Field, C. B. \& Moldan, B.) Ch. 3, 15-46 (Island, Washington DC, 2003).

21. Gruber, N. in Nitrogen in the Marine Environment 2nd edn (eds Capone, D. G., Bronk, D. A Mulholland, M. R. \& Carpenter, E.) Ch. 1 (Academic, San Diego, in the press)

22. Blunier, T. \& Brook, E. J. Timing of millenial-scale climate change in Antarctica and Greenland during the last glacial period. Science 291, 109-112 (2001).

23. Siegenthaler, U. et al. Stable carbon cycle-climate relationship during the Late Pleistocene. Science 310, 1313-1317 (2005).

Acknowledgements This work was supported by funds from ETH Zurich. We thank J. Flückiger for helping us with the ice-core records.

Author Information Reprints and permissions information is available at npg.nature.com/reprints. Correspondence should be addressed to N.G. (nicolas.gruber@env.ethz.ch). 